\section{Easy way of keeping hairs away while suturing ear lacerations}

\section{Sir,}

Ear lacerations are common with the ever increasing road traffic accidents. Domestic injuries and human as well as animal bites also commonly affect ears due to the prominent place they acquire on the face. Auriculoplasties, ear keloids and split lobes also frequently need surgical intervention.

Ear has excellent vascularity and almost near total avulsions usually survive completely. Suturing them is possible under local anaesthesia as well. Only problem we commonly encounter is of the hairs coming into our operating field now and then.

We propose a simple technique to keep the hairs away from the operative field. We routinely use the suture cover (whichever suture is being used for surgery) for this purpose [Figure 1a]. This is readily available sterile material that is usually discarded. The part of the cover that is to be stripped to get the suture out as shown by red arrow in Figure 1a is completely detached. The slot can be made larger if needed just by cutting additional paper
Figure 1b. The slot is adjusted around the ear with larger flap on posterior side and the upper edge is slipped in under the drapes as in Figure 1c. The slot can be made larger if needed just by cutting additional paper. This simple technique keeps the hairs away from the field.

Case presented here is a 35 years female sustaining right ear lacerations following wind shield injury [Figure 2a]. Hairs kept coming in the operative area when we thought of this method [Figure $2 \mathrm{~b}$ ]. It makes the procedure very simple. The splint can be kept in place till the dressing is complete as shown in Figure 2c.

Rahul K. Patil

Department of Plastic and Reconstructive Surgery, Jubilee Mission Medical College, Thrisssur, Kerala, India

Address for correspondence:

Dr. Rahul Patil, Department of Plastic and Reconstructive Surgery, Jubilee Mission Medical College Hospital, East Fort, Thrissur, Kerala - 680 005, India. E-mail: doctrahul@yahoo.co.in

\begin{tabular}{|l|l|}
\multicolumn{2}{c|}{ Access this article online } \\
\hline Quick Response Code: & Website: \\
\hline
\end{tabular}

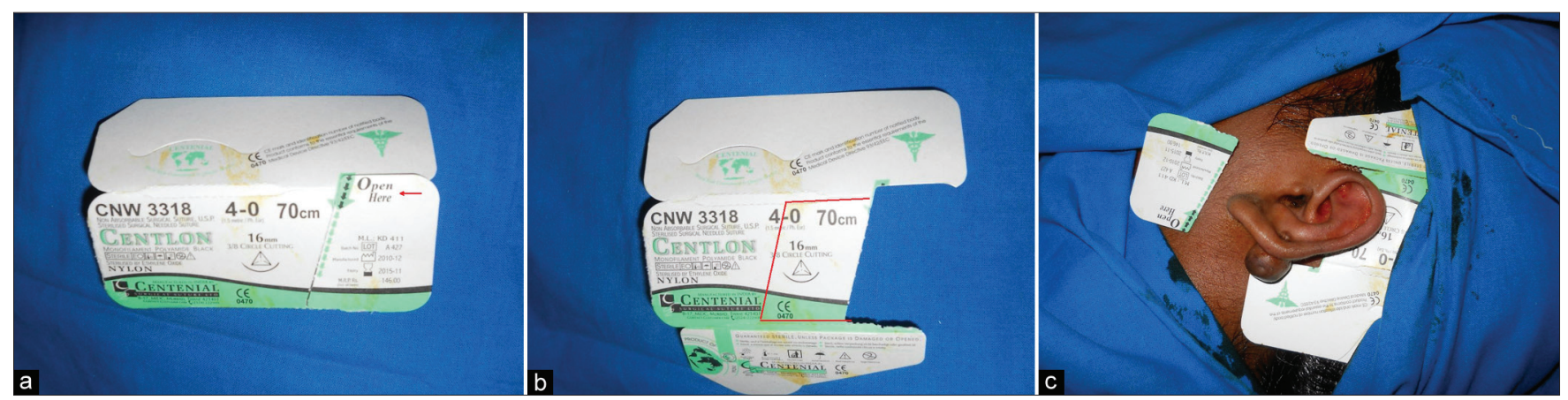

Figure 1: (a) Suture cover of 4'0 Nylon. The red mark points to the flap that is commonly truned down to get out the suture. (b) After removing the flap it is a readymade hair splinting device. If one needs greater depth that can be easily achieved by cutting deep, with scissors as shown by red line. (c) Splint applied to the ear
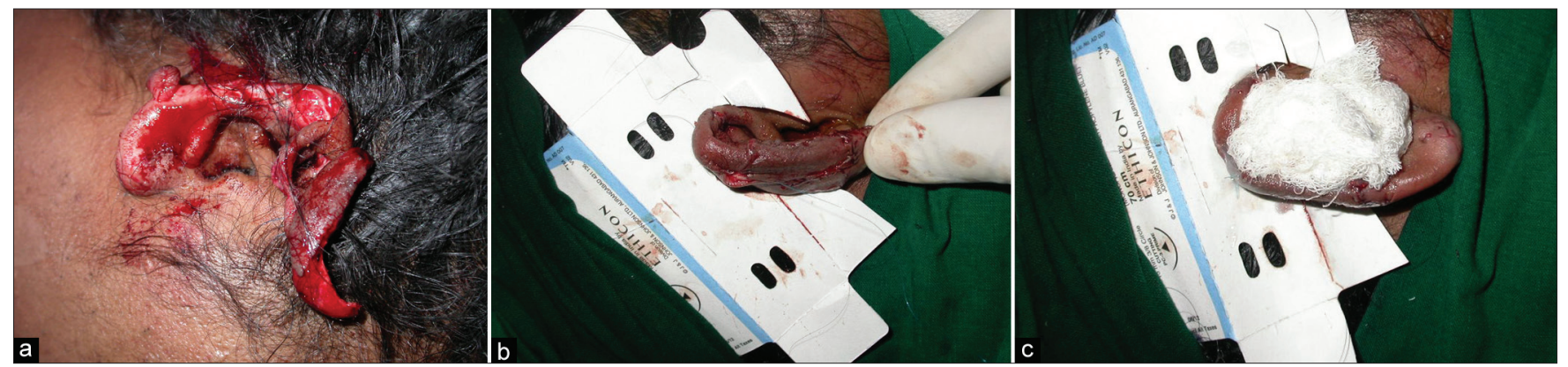

Figure 2: (a) A 35-year-old female with multiple ear lacerations. Hairs can be seen contaminating the field. (b) Following the splint application the suturing becomes quite easy. (c) Following suturing, the dressing has been placed before the splint is removed 